\title{
The L-type calcium channel current modulation mechanism: the plot thickens and fogs
}

\author{
Brooke M. Ahern and Jonathan Satin \\ Department of Physiology, University of Kentucky College of Medicine, Lexington, Kentucky, USA.
}

\begin{abstract}
Stressful situations provoke the fight-or-flight response, incurring rapid elevation of cardiac output via activation of protein kinase $A$ (PKA). In this issue of the $J C l$, Yang et al. focus on the L-type calcium channel complex (LTCC), and their findings require reexamination of dogmatic principles. LTCC phosphorylation sites identified and studied to date are dispensable for PKA modulation of LTCC; however, a $\mathrm{Ca}_{v} \beta_{2}-\mathrm{Ca}_{v} 1.2$ calcium channel interaction is now shown to be required. Yang et al. suggest a new hypothesis that LTCC modulation involves rearrangement of auxiliary proteins within the LTCC. However, we still do not know the targets of PKA that mediate LTCC modulation.
\end{abstract}

\section{Ca $\beta_{2}$ : a critical auxiliary} protein in the heart

The acute stress response, colloquially referred to as the fight-or-flight response, initiates with a burst of sympathetic nervous system (SNS) activity resulting in elevated catecholaminergic signaling. $\beta$-adrenergic receptors ( $\beta$-ARs) on cardiomyocytes transmit SNS activity into elevated cardiac output. The L-type calcium channel complex (LTCC) is an initial proximal effector of $\beta$-AR activation in the myocardium. Catecholaminergic activation of $\beta$-ARs results in increased $\mathrm{Ca}^{2+}$ current through the LTCC $\left(\mathrm{I}_{\mathrm{Ca}, \mathrm{L}}\right)$ with channel activation occurring at lower membrane voltage. The net effect is increased $\mathrm{I}_{\mathrm{Ca}, \mathrm{L}}$, resulting in accentuated excitation-contraction coupling in the ventricle and faster spontaneous depolarization in the sinoatrial node, thus contributing to increased contraction and faster heart rate, respectively. This increased $\mathrm{I}_{\mathrm{Ca}, \mathrm{L}}$ by $\beta$-AR signaling is commonly called modulation. Despite the central physiological importance of $\mathrm{Ca}_{\mathrm{v}} 1.2$ modulation combined with extensive investigations to uncover molecular mechanisms of action, we still don't know how the LTCC is modulated.
The LTCC is a heteromultimeric protein complex. In the myocardium, $\mathrm{Ca}_{\mathrm{v}} 1.2$ is the major pore-forming subunit. In older literature, this has been called the $\alpha$-subunit. An additional array of proteins directly and/or indirectly complex with $\mathrm{Ca}_{\mathrm{v}} 1.2(1) . \mathrm{Ca}_{\mathrm{v}} \beta$, specifically $\mathrm{Ca}_{\mathrm{v}} \beta_{2}$ in the heart, is a critical auxiliary protein (2). For heterologous expression systems, coexpression of $\alpha$ - and $\beta$-subunits is necessary and sufficient to recapitulate a near-native $\mathrm{I}_{\mathrm{Ca}, \mathrm{L}}$; however, it has not been possible to reproduce $\mathrm{Ca}_{\mathrm{v}} 1.2$ modulation in heterologous systems (3). One interpretation is that key accessory proteins required for modulation are not present in heterologous expression systems. Regardless, the ability of $\mathrm{Ca}_{\mathrm{v}} \beta$ to increase $\mathrm{Ca}_{\mathrm{v}} 1.2$ trafficking in heterologous expression systems, and to modify $\mathrm{Ca}_{\mathrm{v}} 1.2$ gating underscores the central contribution of $\mathrm{Ca}_{\mathrm{v}} \alpha-\mathrm{Ca}_{\mathrm{v}} \beta$ interactions for LTCC function (4). The linker between repeat segments I and II on $\mathrm{Ca}_{\mathrm{v}} 1.2$ contains a so-called $\underline{\alpha}$-interaction domain (AID) that confers a biochemically stable complex between $\mathrm{Ca}_{\mathrm{v}} 1.2$ and $\mathrm{Ca}_{\mathrm{v}} \beta_{2}$. Thus, first principles suggest that

Related Article: p. 647

Conflict of interest: The authors have declared that no conflict of interest exists.

Reference information: J Clin Invest. 2019;129(2):496-498. https://doi.org/10.1172/JCI125958.

the $\alpha-\beta$ subunit interaction predominates interactions among a sea of multiple proteins that comprise the LTCC complex.

Decades of study unequivocally support active protein kinase A (PKA) as the link from $\beta$-AR activation to $\mathrm{Ca}_{\mathrm{v}} 1.2$ modulation (5). PKA is a kinase, thus spurring the search for substrate sites within the LTCC that might be critical to transduce $\mathrm{Ca}_{\mathrm{v}} 1.2$ modulation. In this edition of the JCI, Yang et al. continue to exploit a clever experimental system to reveal more of what we still don't know about $\mathrm{Ca}_{\mathrm{v}} 1.2$ modulation (6). They introduce a transgene in mice to overexpress a $\mathrm{Ca}_{\mathrm{v}} 1.2$ construct containing a dihydropyridine-insensitive mutation. This so-called pseudo-WT (pWT) channel is transcriptionally activated from a tetracycline-inducible promoter to allow limited temporal overexpression of $\mathrm{Ca}_{\mathrm{v}} 1.2$ in the myocardium. The use of nisoldipine then allows dissection of transgene driven from endogenous $\mathrm{I}_{\mathrm{Ca}, \mathrm{L}}$. As long as there are no rapid remodeling events in the heart, then outcomes can be interpreted as occurring in healthy ventricular cardiomyocytes. By adding mutations onto the $\mathrm{Ca}_{\mathrm{v}} 1.2-\mathrm{AID}$, the authors were able to interrogate adult ventricular cardiomyocyte $\mathrm{I}_{\mathrm{Ca}, \mathrm{L}}$ carried by mutant $\mathrm{Ca}_{\mathrm{v}}$ 1.2. The outcomes using this transgenic strategy are unexpected and quite frankly, surprising.

\section{Are all known PKA substrate phosphor-serine residues dispensable for modulation?}

Apparently, the brief answer to the above posed question is simply, yes. Studies of single established $\mathrm{Ca}_{\mathrm{v}} 1.2$ PKA-mediated phosphorylation sites eliminated the requirement for $\mathrm{Ca}_{\mathrm{v}} 1.2$ sites Ser1928 (7), Ser1700, and Thr1704 (8) as well as $\mathrm{Ca}_{\mathrm{v}} \beta$ sites Ser459, Ser478, and Ser479 (9). The present work and most recent past publications from the Marx group eliminate many (if not all) of the prospective phosphorylation sites on $\mathrm{Ca}_{\mathrm{v}} 1.2$ in unison, yet modulation still occurs $(8,10)$. Their 
A

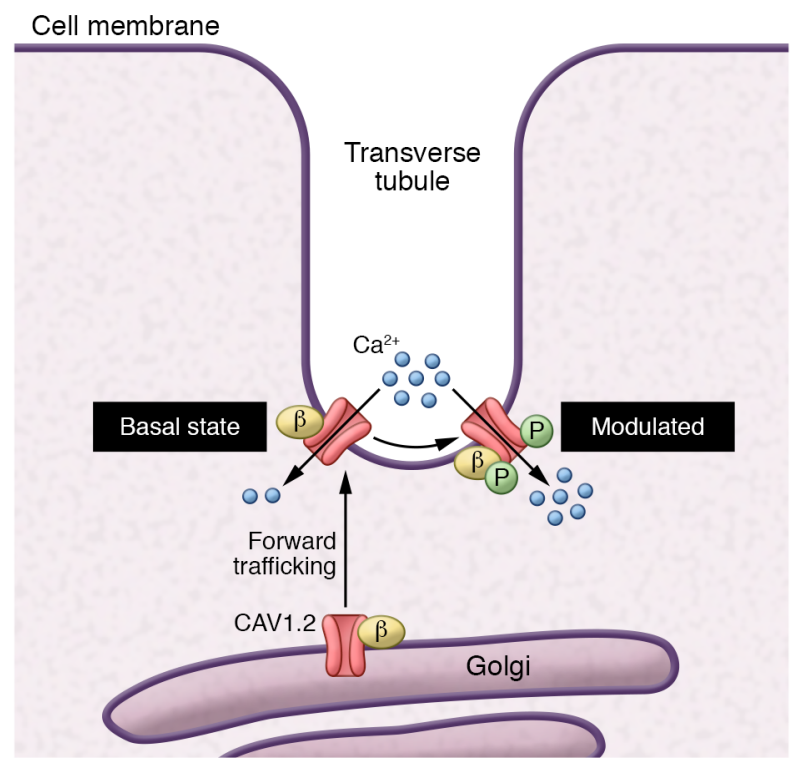

B

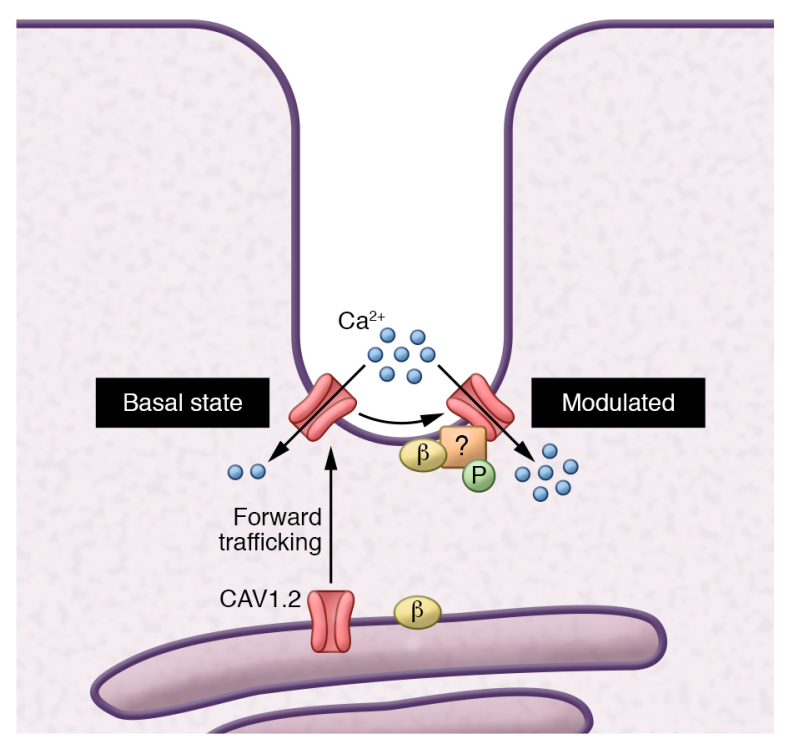

Figure 1. $\mathrm{Ca}_{\mathrm{v}} \boldsymbol{\beta}_{2}-\mathrm{Ca}_{\mathrm{v}} 1.2$ interaction is not required for forward trafficking, but is required for $\mathrm{Ca}_{\mathrm{v}} 1.2$ modulation by PKA. (A) Old dogma: $C a_{v} \beta-C a_{v} \alpha$ interaction on the Golgi apparatus promotes forward trafficking. $\mathrm{Ca}_{\mathrm{v}} 1.2$ in the transverse tubules is modulated by one or more phosphoregulatory sites on $C a_{\mathrm{v}} 1.2$ and/or $\mathrm{Ca}_{v} \beta_{2}$. (B) New paradigm: $\mathrm{Ca}_{v} \beta-\mathrm{Ca}_{v} \alpha$ interaction is not required for forward trafficking, and in the transverse tubules Ca 1.2 modulation requires $\mathrm{Ca}_{\mathrm{v}} \beta$, and perhaps additional accessory subunits.

latest work using $\mathrm{Ca}_{\mathrm{v}}$ 1.2-AID mutations to prevent $\alpha-\beta$ interaction convincingly demonstrates a requirement for $\alpha-\beta$ interaction to confer $\mathrm{I}_{\mathrm{Ca}, \mathrm{L}}$ modulation. This suggests that modulation via key protein-protein interactions, rather than one or more phosphoregulatory sites on $\mathrm{Ca}_{\mathrm{v}} 1.2$ or $\mathrm{Ca}_{\mathrm{v}} \beta_{2}$ are involved (Figure 1). If no known phosphorylation events are identifiable as mechanisms of modulation, then which protein interactions confer a modulated $\mathrm{I}_{\mathrm{Ca}, \mathrm{L}}$ ? Moreover, why are $\mathrm{Ca}_{\mathrm{v}} 1.2-\mathrm{Ser} 1928$ and -Ser1701 conserved and phosphorylated by PKA? It is hard to understand what selection pressure exists to conserve the utilization of these sites across species. One speculative explanation might hold that nonmyocardial $\mathrm{I}_{\mathrm{Ca}, \mathrm{L}}$ modulation has differential mechanisms of modulation. For example, Ser1928 is essential for $\beta_{2}$-AR signaling in neurons (11) and vascular smooth muscle (12). Application of Yang et al.'s transgene system in noncardiomyocytes would be an interesting test of the hypothesis that $\mathrm{Ca}_{\mathrm{v}} 1.2$ phosphor-serine site conservation is attributable to essential nonmyocardial modulation mechanisms. Then the implication is that the LTCC heteromultimeric complex constituents differ across tissues.
$C a_{\mathrm{v}} \beta$ : dispensable for trafficking?

$\mathrm{Ca}_{\mathrm{v}} 1.2$ forward trafficking dogma holds that $\mathrm{Ca}_{\mathrm{v}} \beta$ promotes localizing $\mathrm{Ca}_{\mathrm{v}} 1.2$ to surface membrane (4). Early studies based on heterologous systems demonstrated that the $\beta$ subunit acts as a chaperone for $\mathrm{Ca}_{\mathrm{v}} 1.2$ to exit the Golgi complex and stabilizes channel complexes once in the membrane (13-15). More recent work, also in heterologous expression systems, attributes forward trafficking function to $\alpha-\beta$ interaction (16). By contrast in this issue of the JCI, Yang et al. show that subcellular localization of $\mathrm{Ca}_{\mathrm{v}} 1.2$ was unaffected and peak $\mathrm{Ca}^{2+}$ currents increased when $\mathrm{I}_{\mathrm{Ca}, \mathrm{L}}$ was measured from LTCC with $\mathrm{Ca}_{\mathrm{v}}$ 1.2-AID-mutant channels (6). In other words, the assumption is that forward trafficking was unaffected under conditions whereby $\alpha-\beta$ interaction could not occur. A reasonable interpretation is that $\alpha-\beta$ is dispensable for forward trafficking in cardiomyocytes (Figure 1). There are, however, some idiosyncrasies in this innovative approach. For example, pseudo-WT and AID-mutant $\mathrm{Ca}_{\mathrm{v}} 1.2$ cardiomyocytes display a smaller percentage of contraction compared with that of nontransgenic cardiomyocytes, even though pWT and AID have increased $\mathrm{Ca}^{2+}$ currents. It is clear that $\mathrm{Ca}_{\mathrm{v}} 1.2 \mathrm{AID}$ mutants can trigger excitation-contraction coupling, but the quantitative mismatch is a puzzling issue worthy of speculation. Recent studies showed that the location of L-type calcium channels within the cardiomyocyte could determine how calcium is used by the cell. Channel complexes in transverse tubules may be the source of contractile $\mathrm{Ca}^{2+}$, whereas channel complexes in caveolin-3 contribute to signaling $\mathrm{Ca}^{2+}$ (17). In cells from failing hearts, channel complexes dislocate to the sarcolemma surface, which could promote arrhythmias and contribute to the pathophysiology of heart failure (18). In this vein, it would be interesting to determine whether $\mathrm{Ca}_{\mathrm{v}} \beta$ is dispensable for compartment-specific trafficking such as might be altered during pathological remodeling.

\section{Conclusions}

Assuming that the transgenic system employed by Yang et al. recapitulates native LTCC complexes with high fidelity leads us to two broad conclusions that require reevaluation of mechanisms of modulation and LTCC cell biology. First, the necessity of an $\alpha-\beta$ interaction for $\mathrm{I}_{\mathrm{Ca}, \mathrm{L}}$ modulation without an identifiable PKA substrate site suggests the novel idea that signal transduction from PKA activation to $\mathrm{I}_{\mathrm{Ca}, \mathrm{L}}$ modulation requires key protein-protein interactions. This does not obviate the earlier pervasive notion that 
$\mathrm{Ca}_{\mathrm{v}} 1.2$ (or $\mathrm{Ca}_{\mathrm{v}} \beta_{2}$ ) phosphorylation triggers allosteric effects resulting in modulation; rather, this work highlights the importance of consideration of LTCC protein-protein interactions, which can plausibly extend beyond $\alpha-\beta$ subunit interactions. However, we still don't know the relevant mechanism for modulation. The second conclusion from this study highlights the perils of relying on reductionist heterologous expression systems to recapitulate the cell biology of native heteromultimeric complexes such as the LTCC. Indeed, heterologous expression systems fail to recapitulate modulation, and this new study suggests that earlier trafficking studies require cautious interpretation because of the discordant finding that $\mathrm{Ca}_{\mathrm{v}} \beta$ promotes forward trafficking in reduced systems but is not necessary in cardiomyocytes. The one issue to temper enthusiasm for the Yang et al. transgenic system is that there is stoichiometric overexpression of the $\alpha$-subunit. It is a metaphorical application of the Heisenberg uncertainty principle loosely extended to the biological realm. In this case, to study native LTCC we need to overexpress a single subunit, thus potentially changing the balance of proteins in the LTCC heteromultimeric complex.

In summary, the work of Yang et al. eliminated the usual suspects of phosphorylation sites required for $\mathrm{I}_{\mathrm{Ca}, \mathrm{L}}$ modulation, and raised the specter of a mechanism involving multiple protein interactions with the LTCC complex; however, which proteins might be essential beyond $\alpha-\beta$ interaction, along with relevant PKA substrates for $\mathrm{I}_{\mathrm{Ca}, \mathrm{L}}$ modulation, remain foggy.

\section{Acknowledgments}

This work is supported by NIH grant HL131782 and grant T32 GM118292 (to BMA).

Address correspondence to: Jonathan Satin, Department of Physiology, University of Kentucky College of Medicine, 800 Rose Street, Lexington, Kentucky 405360298, USA. Phone: 859.323.5356. Email: jsatin1@uky.edu.

1. Satin J. Regulation of cardiac calcium channels. In: Zipes DP, Jalife J, Stevenson WG, eds. Cardiac Electrophysiology: From Cell to Bedside. 7th ed. Philadelphia, Pennsylania, USA: Elsevier; 2017:96-105.

2. Foell JD, et al. Molecular heterogeneity of calcium channel beta-subunits in canine and human heart: evidence for differential subcellular localization. Physiol Genomics. 2004;17(2):183-200.

3. Wei SK, et al. $\mathrm{Ca}^{2+}$ channel modulation by recombinant auxiliary $\beta$ subunits expressed in young adult heart cells. Circ Res. 2000;86(2):175-184.

4. Gerster U, Neuhuber B, Groschner K, Striessnig J, Flucher BE. Current modulation and membrane targeting of the calcium channel $\alpha 1 \mathrm{C}$ subunit are independent functions of the $\beta$ subunit. J Physiol (Lond). 1999;517(Pt 2):353-368.

5. Kamp TJ, Hell JW. Regulation of cardiac L-type calcium channels by protein kinase A and protein kinase C. Circ Res. 2000;87(12):1095-1102.

6. Yang L, et al. Cardiac $\mathrm{Ca}_{\mathrm{v}} 1.2$ channels require $\beta$ subunits for $\beta$-adrenergic-mediated modulation but not trafficking. J Clin Invest. 2019;129(2):647-658.

7. Ganesan AN, Maack C, Johns DC, Sidor A, O'Rourke B. Beta-adrenergic stimulation of L-type $\mathrm{Ca}^{2+}$ channels in cardiac myocytes requires the distal carboxyl terminus of alpha1C but not serine 1928. Circ Res. 2006;98(2):e11-e18.

8. Yang L, Katchman A, Samad T, Morrow J, Weinberg R, Marx SO. $\beta$-Adrenergic regulation of the L-type $\mathrm{Ca}^{2+}$ channel does not require phosphoryla- tion of $\alpha 1 C$ Ser1700. Circ Res. 2013;113(7):871-880.

9. Brandmayr J, et al. Deletion of the C-terminal phosphorylation sites in the cardiac $\beta$-subunit does not affect the basic $\beta$-adrenergic response of the heart and the $\mathrm{Ca}(\mathrm{v}) 1.2$ channel. J Biol Chem. 2012;287(27):22584-22592.

10. Katchman A, et al. Proteolytic cleavage and PKA phosphorylation of $\alpha_{1 C}$ subunit are not required for adrenergic regulation of $\mathrm{Ca}_{\mathrm{v}} 1.2$ in the heart. Proc Natl Acad Sci U S A . 2017;114(34):9194-9199.

11. Qian H, et al. Phosphorylation of Ser1928 mediates the enhanced activity of the L-type $\mathrm{Ca}^{2+}$ channel $\mathrm{Ca}_{\mathrm{v}} 1.2$ by the $\beta 2$-adrenergic receptor in neurons. Sci Signal. 2017;10(463):eaaf9659.

12. Nystoriak MA, et al. Ser1928 phosphorylation by PKA stimulates the L-type $\mathrm{Ca}^{2+}$ channel $\mathrm{Ca}_{\mathrm{v}} 1.2$ and vasoconstriction during acute hyperglycemia and diabetes. Sci Signal. 2017;10(463):eaaf9647.

13. Chien AJ, et al. Roles of a membrane-localized $\beta$ subunit in the formation and targeting of functional L-type $\mathrm{Ca}^{2+}$ channels. J Biol Chem. 1995;270(50):30036-30044.

14. Brice NL, et al. Importance of the different $\beta$ subunits in the membrane expression of the $\alpha 1 \mathrm{~A}$ and $\alpha 2$ calcium channel subunits: studies using a depolarization-sensitive $\alpha 1 \mathrm{~A}$ antibody. Eur J Neurosci. 1997;9(4):749-759.

15. Yamaguchi H, Hara M, Strobeck M, Fukasawa K, Schwartz A, Varadi G. Multiple modulation pathways of calcium channel activity by a $\beta$ subunit. Direct evidence of $\beta$ subunit participation in membrane trafficking of the $\alpha 1 \mathrm{C}$ subunit. J Biol Chem. 1998;273(30):19348-19356.

16. Rusconi F, et al. Peptidomimetic targeting of Cav $\beta 2$ overcomes dysregulation of the L-type calcium channel density and recovers cardiac function. Circulation. 2016;134(7):534-546.

17. Makarewich CA, et al. A caveolae-targeted L-type $\mathrm{Ca}^{2+}$ channel antagonist inhibits hypertrophic signaling without reducing cardiac contractility. Circ Res. 2012;110(5):669-674.

18. Sanchez-Alonso JL, et al. Microdomain-specific modulation of L-type calcium channels leads to triggered ventricular arrhythmia in heart failure. Circ Res. 2016;119(8):944-955. 